\title{
Velcrand Functionalized Polyethylene
}

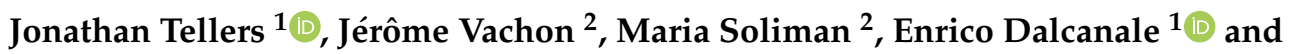 \\ Roberta Pinalli ${ }^{1, *(1)}$ \\ 1 Department of Chemistry, Life Sciences and Environmental Sustainability, University of Parma, and INSTM, \\ UdR Parma, Parco Area delle Scienze 17/A, 43124 Parma, Italy; jonathan.tellers@studenti.unipr.it (J.T.); \\ enrico.dalcanale@unipr.it (E.D.) \\ 2 SABIC Europe B.V., Urmonderbaan 22, 6160 AH Geleen, The Netherlands; jerome.vachon@sabic.com (J.V.); \\ maria.soliman@sabic.com (M.S.) \\ * Correspondence: roberta.pinalli@unipr.it; Tel.: +39-0521-905464
}

Received: 11 February 2019; Accepted: 1 March 2019; Published: 5 March 2019

\begin{abstract}
Velcrands are a specific class of cavitands whose complementary surfaces induce self-dimerization. The insertion of a velcrand as physical cross-linking unit into a polymer is reported. To this purpose, the velcrand was functionalized at the lower rim with an isocyanate group. The functional velcrand was reacted with poly (ethylene-co-(2-hydroxethylmethacrylate)) (PE-HEMA), a polymer equipped with free hydroxyl groups suitable for reaction with the isocyanate group. The obtained functionalized polymer was characterized by nuclear magnetic resonance (NMR), differential scanning calorimetry (DSC), and Fourier transform infrared spectroscopy (FTIR), proving the introduction of velcraplexes in the polymer. Films with varying amounts of velcrands were obtained by solution casting and slow evaporation, testifying the processability of the functionalized polymers. The obtained films were used to measure the oxygen barrier properties of the functionalized material.
\end{abstract}

Keywords: velcrand; polyethylene; quinoxaline cavitand; PE-HEMA

\section{Introduction}

Cavitands are programmable synthetic receptors capable of hosting shape complementary guests through specific weak interactions, such as hydrogen bonding, $\pi-\pi$ stacking, and $\mathrm{CH}-\pi$ and cation- $\pi$ interactions [1]. Their remarkable and versatile molecular recognition properties have been exploited in many different fields, including catalysis [2-5], crystal engineering [6], molecular grippers [7], amino acids $[8,9]$ and protein recognition $[10,11]$, responsive nanostructures [12,13], and sensing [14,15].

Among the cavitand family, quinoxaline cavitands occupy a unique position due to their peculiar ability to change their conformation in response to external stimuli, like $\mathrm{pH}$ and temperature [16]. In fact, these macrocycles are able to reversibly interconvert between a closed vase conformation and an open extended kite one [17]. The introduction of four methyl groups at the upper rim of the resorcinarene scaffold stabilizes the kite conformer and induces its dimerization to form velcaplexes [18].

Early attempts to turn velcrands into polymeric materials relied on solvophobic interactions ( $\pi-\pi$ stacking) present between quinoxaline cavitands in the kite form [18], either as heteroditopic or homoditopic monomers. In the first case, the second interaction mode was a metal coordination between pyridines inserted at the lower rim of the kite cavitand and suitable Pd complexes precursors $[19,20]$ or a ureidopyrimidone (UPy) unit which self-dimerizes via quadruple H-bonding [21]. In the second case, two velcrands were covalently linked to form an homoditopic monomer [22]. In all cases the interaction strength was sufficient to generate oligomers, but not polymers. No attempts were made so far to insert velcraplexes into preformed polymers as physical cross-linking units.

Here we report the synthesis and characterization of a velcrand-grafted polyethylene. Polyethylene is one of the most important polymers world-wide, thus any research effort to improve their functionality, 
like the introduction of physical cross-links, is highly desired. We foresee potential benefits regarding the oxygen barrier properties of functionalized films thanks to the supramolecular cross-linking. Typically, the major contribution to the oxygen barrier properties of polymers is the tortuous pathway that oxygen will have to travel inside the polymer matrix [23]. Here, the considerably large velcrand molecules could provide an obstacle for the oxygen traveling inside the matrix, effectively increasing the barrier properties by additional physical cross-linking, like hydrogen-bonding in ethylene vinyl alcohol (EVOH) but without humidity interference.

\section{Results and Discussion}

For the preparation of velcrand cross-linked polyolefins, polymers bearing moieties suitable for grafting of the velcrands through a reliable, high yield reaction are required. Urethane was chosen as the linking unit because it can be easily obtained by reaction of an isocyanate with a primary alcohol. Poly (ethylene-co-(2-hydroxethylmethacrylate)) (PE-HEMA), a co-polymer of ethylene and 2-hydroxyethylmethacrylate (HEMA), was selected for this purpose. It has free pendant primary hydroxyl groups which can easily react with isocyanate functionalized velcrands. HEMA content is only $0.91 \mathrm{~mol} \%$, so to be as close as possible to a true polyethylene.

A self-dimerizing velcrand with a relatively large $\mathrm{K}_{\mathrm{a}}$ of $8.5 \cdot 10^{4} \mathrm{M}^{-1}$ (measured in chloroform at room temperature) was employed in this study (Figure 1, Scheme 1) [18,24]. The velcrand is functionalized at the upper rim with four methylene groups, which forces it to assume a permanent kite conformation (velcrand) suitable for dimer formation. The driving forces for dimerization are dipole-dipole, van der Waals, and solvophobic interactions [18]. For polymer insertion, the velcrand was functionalized at the lower rim with an isocyanate group that is suitable for reaction with the free hydroxyl pendant groups of PE-HEMA.

A

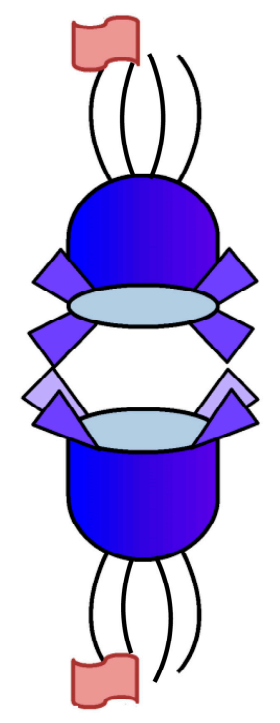

B

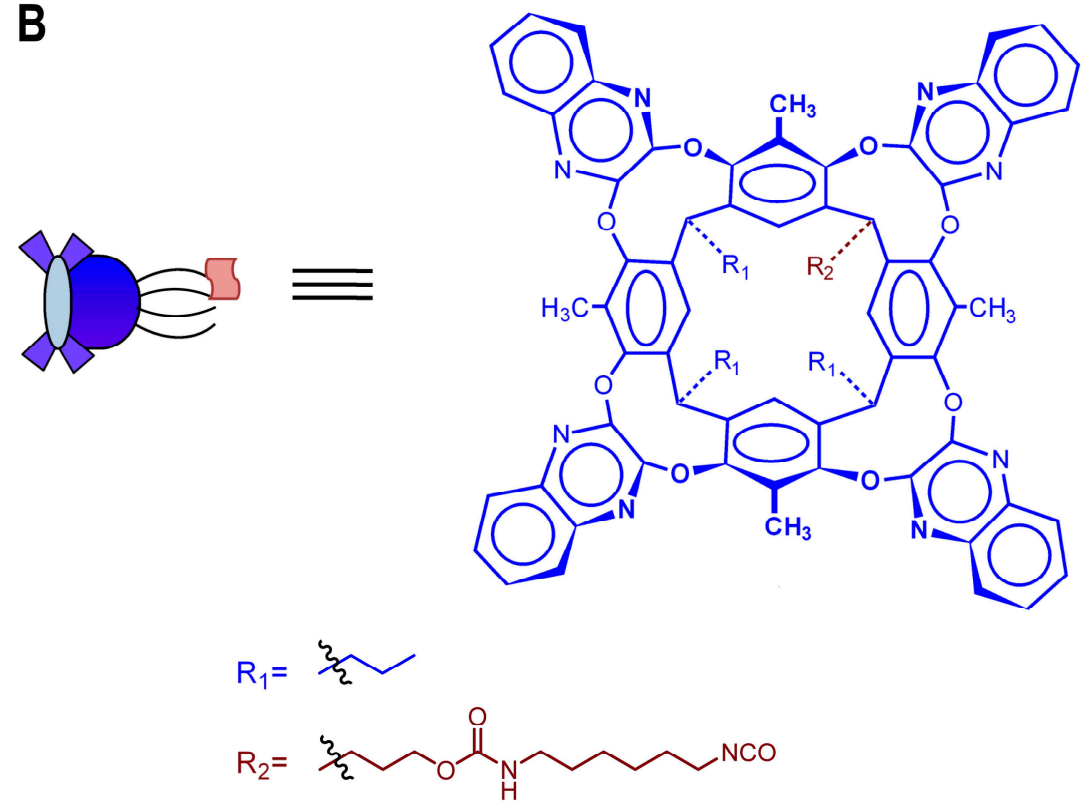

Figure 1. A: Illustration of dimerization of self-complementary velcrand. B: Structure of self-dimerizing velcrand with isocyanate chain for introduction into functional polymers. 


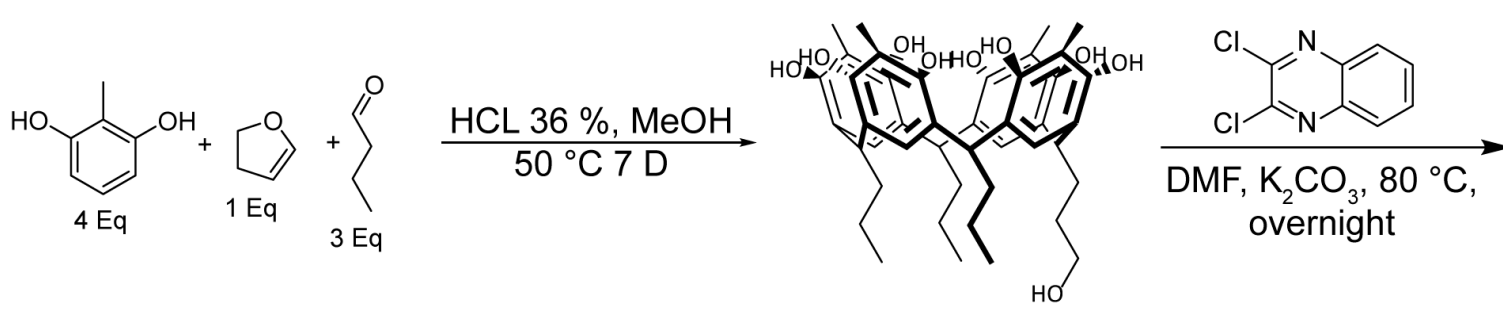

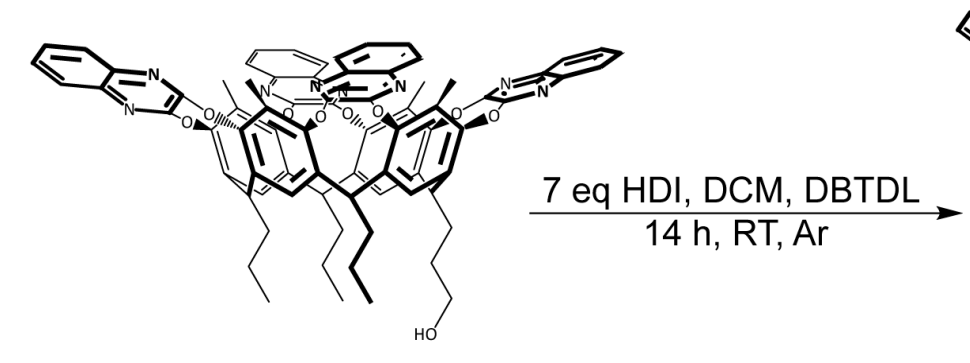

4QxCavOH

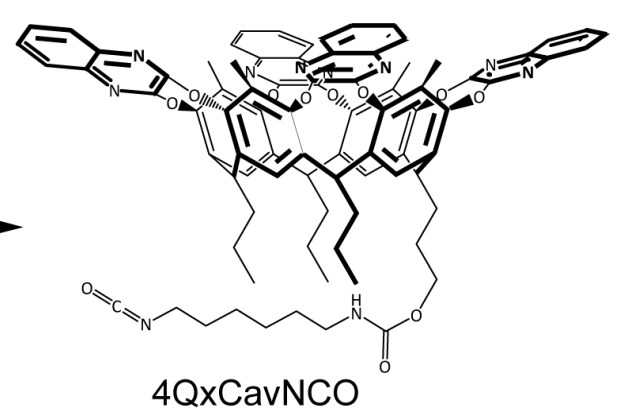

Scheme 1. Scheme for the synthesis of mono-isocyanate functionalized 4QxKite velcrand (4QxCavNCO).

\subsection{Design and Synthesis of the Velcrand}

A resorcinarene functionalized at the lower rim with a hydroxyl group was prepared by reacting 4 equivalents of 2-methylresorcinol with 1 equivalent of 2,3-dihydrofuran and 3 equivalents of butyraldehyde, in methanol as solvent, and concentrated hydrochloric acid. This procedure leads to a mixture of resorcinarenes with zero to two hydroxyl groups at the lower rim. The crude resorcinarene mixture was directly used in the next step, eliminating an additional purification. The crude was reacted overnight at $80^{\circ} \mathrm{C}$ with a slight excess of 2,3-dichloroquinoxaline in dimethylformamide (DMF), and in the presence of potassium carbonate as base. The desired velcrand equipped with a single hydroxyl group at the lower rim, hitherto referred to as $4 \mathrm{QxCavOH}$ (Scheme 1), was isolated via column chromatography. To obtain the desired isocyanate functional velcrand, 4QxCavOH was reacted with an excess of hexamethylene diisocyanate (HDI) in the presence of dibutyltin dilaurate (DBTDL) acting as a catalyst. The isocyanate functionalized velcrand, namely $4 \mathrm{QxCavNCO}$, was isolated by precipitation in hexane with a yield of $69 \%$ (Scheme 1).

\subsection{Synthesis and Characterization of Velcrand Functional Polymer Networks}

PE-HEMA with $0.91 \mathrm{~mol} \%$ hydroxyl groups was selected as suitable polymer. The functionalized polymers were obtained by reacting PE-HEMA with the isocyanate functional velcrand according to the following procedure. PE-HEMA was dissolved in toluene at $80{ }^{\circ} \mathrm{C}$, then $4 \mathrm{QxCavNCO}$ was added (in wt $\%$ ), followed by the addition of few drops of DBTDL as catalyst. The resulting solution was stirred for $4 \mathrm{~h}$ and subsequently precipitated into hexane, obtaining the functionalized polymer as white powder. An overview of the obtained polymers, the introduced amount of velcrand in $w \mathrm{t} \%$, and DSC data are given in Table 1 . The maximum amount of introduced velcrand, namely $30.6 \mathrm{wt} \%$, corresponds to full functionalization of all the available PE-HEMA hydroxyl groups (0.91 mol\%). Introduction of the velcrand proved to affect the thermal properties of the polymer (Table 1 and Figure 2). The bulky motif reduced the $T_{m}$ and the crystalline degree $\left(X_{c}\right)$ of the pristine polymers, this last one till less than half value for 4QxCav30.6. 
Table 1. Overview of the prepared velcrand functionalized PE, theoretical amount of velcrand introduced in $\mathrm{wt} \%$, and thermal data.

\begin{tabular}{|c|c|c|c|c|c|}
\hline Entry & HEMA $^{\text {a }}(\mathrm{mol} \%)$ & $\begin{array}{c}\text { 4QxCavNCO } \\
(w t \%)\end{array}$ & $\begin{array}{c}\text { OH-Group } \\
\text { Funcionalization (mol\%) }\end{array}$ & $\mathrm{T}_{\mathrm{m}}{ }^{\mathrm{b}}\left({ }^{\circ} \mathrm{C}\right)$ & $X_{c}^{d}(\%)$ \\
\hline 4QxCav0 & 0.91 & - & - & 107.4 & 30.2 \\
\hline 4QxCav1 & 0.91 & 1 & 3 & 107.5 & 29.3 \\
\hline $4 \mathrm{Q} \times$ Cav5 & 0.91 & 5 & 16 & 106.0 & 25.4 \\
\hline 4QxCav30.6 & 0.91 & $30.6^{c}$ & 100 & 96.8 & 11.3 \\
\hline
\end{tabular}
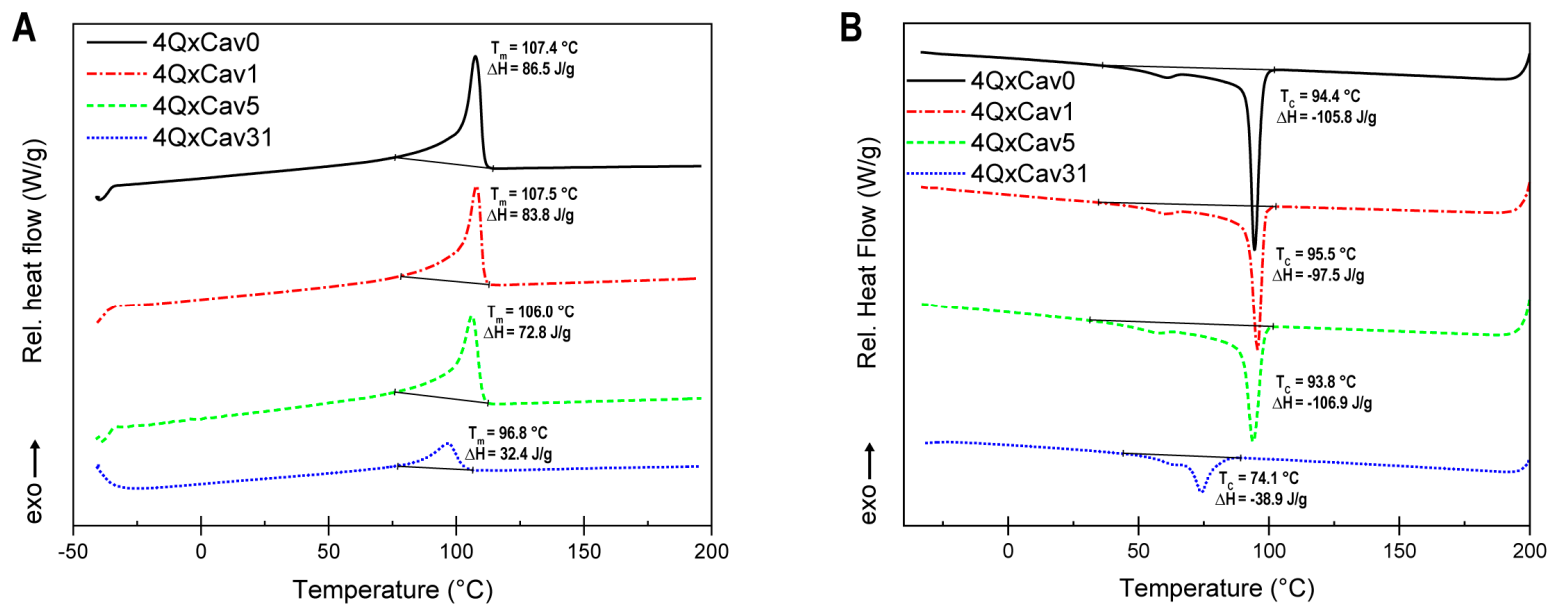

Figure 2. DSC spectra of pristine PE-HEMA and velcrand functionalized samples. A: 2nd heating ramp, from which it is possible to determine the $T_{m}$. B: 2nd cooling ramp from, from which it is possible to determine the $\mathrm{T}_{\mathrm{c}}$.

This observation was not unsuspected, as the bulky velcrand side chains cannot be part of the PE crystal lattice and will keep large part of the chain unavailable for crystallization. Small amounts of velcrand do affect the crystallinity to a lesser extent, as is apparent from sample 4QxCav1 (entry 2, Table 1).

The successful synthesis was confirmed via FTIR and high temperature ${ }^{1} \mathrm{H}$ NMR. In Figure 3 the FTIR spectra of 4QxCavNCO, pristine and functional PE-HEMA are shown. An absorption band for the $\mathrm{OH}$ groups of the HEMA co-monomer is missing in the spectrum of the pristine sample, likely because of the low HEMA content of $0.91 \%$. After reaction, the disappearance of the characteristic NCO stretching band at $2269 \mathrm{~cm}^{-1}$ [26] was observed, indicating the reaction of the NCO groups. In addition, new peaks between $1000 \mathrm{~cm}^{-1}$ and $1400 \mathrm{~cm}^{-1}$ appeared inside the spectrum of the functional polymer labeled 4QxCav30.6 (entry 4, Table 1), which correspond to vibrations of the introduced velcrand. The $\mathrm{C}=\mathrm{O}$ band resulting from the carbamate linkage is overlapping with the preexisting carbonyl $\mathrm{C}=\mathrm{O}$ band of the ester of the pristine polymer.

The attachment of the velcrand to the polymer backbone is confirmed by high temperature ${ }^{1} \mathrm{H}$ NMR. The ${ }^{1} \mathrm{H}$ NMR of pristine PE-HEMA (top spectrum, blue line), 4QxCav30.6 polymer (middle spectrum, red line), and pristine velcrand $4 \mathrm{QxCavNCO}$ (bottom spectrum, green line) are reported in Figure 4. After functionalization, the peaks of pristine PE-HEMA, highlighted by letters a and b (top spectrum, blue line), combine to a single peak (signal with letter $\mathbf{c}$ in the middle spectrum, red line). The signal of methylene close to isocyanate marked by letter $\mathbf{g}$ (bottom spectrum, green line) disappears after functionalization, indicating full functionalization. Due to the overlapping of velcrand and pristine PE-HEMA signals, determination of degree of functionalization was difficult. The ${ }^{1} \mathrm{H}$ NMR spectrum of functionalized 4QxCav30.6 (middle spectrum, red line) reveals that the dimer exists in the kite form inside the polymer matrix as the characteristic split of the arylmethyl signals 
is observed (marked by letter $\mathbf{h}$ in the bottom spectrum of the pristine velcrand and letter $\mathbf{d}$ in the middle spectrum of the functionalized polymer) [18]. It is worth noticing that the velcraplex formation is effective even once attached to the PE matrix.

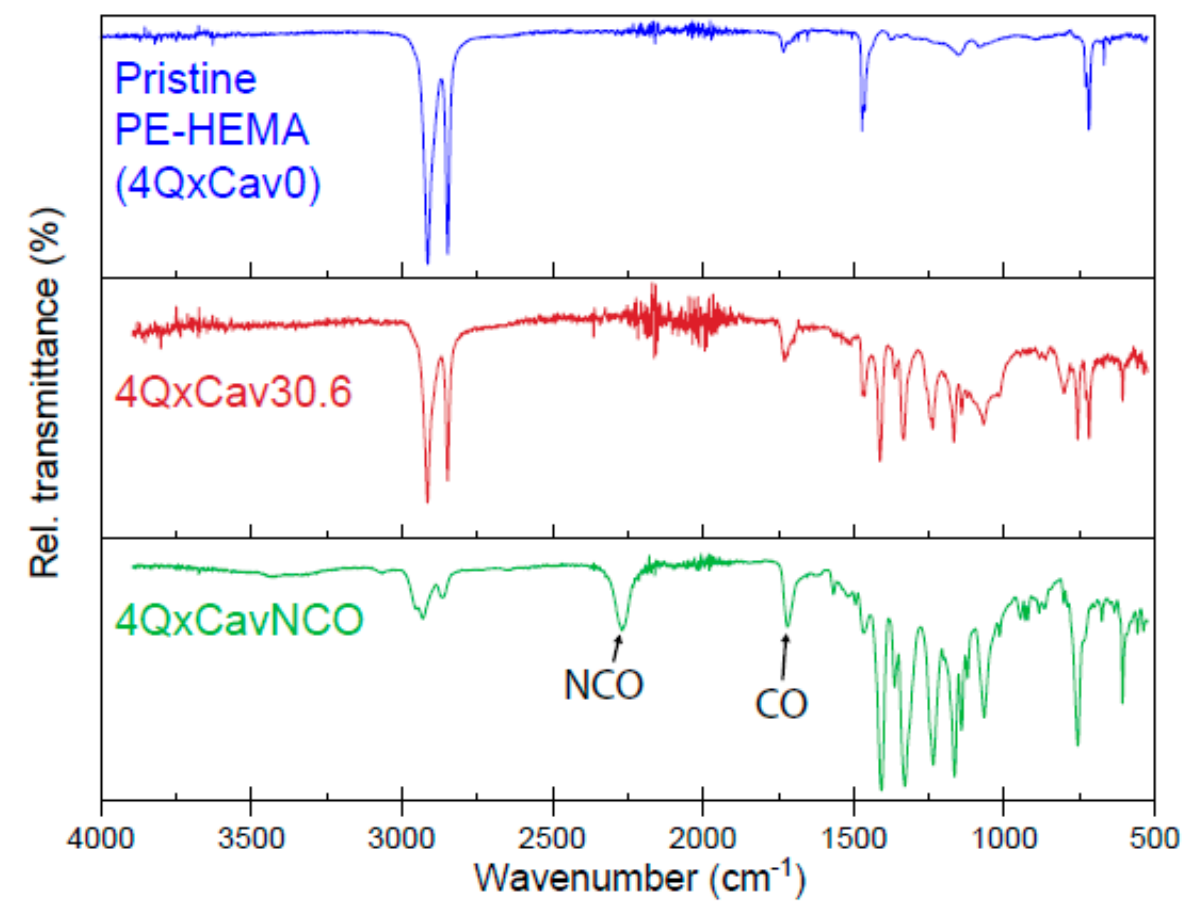

Figure 3. FTIR spectra of pristine PE-HEMA (4QxCav0), 4QxCav30.6, and 4QxCavNCO.

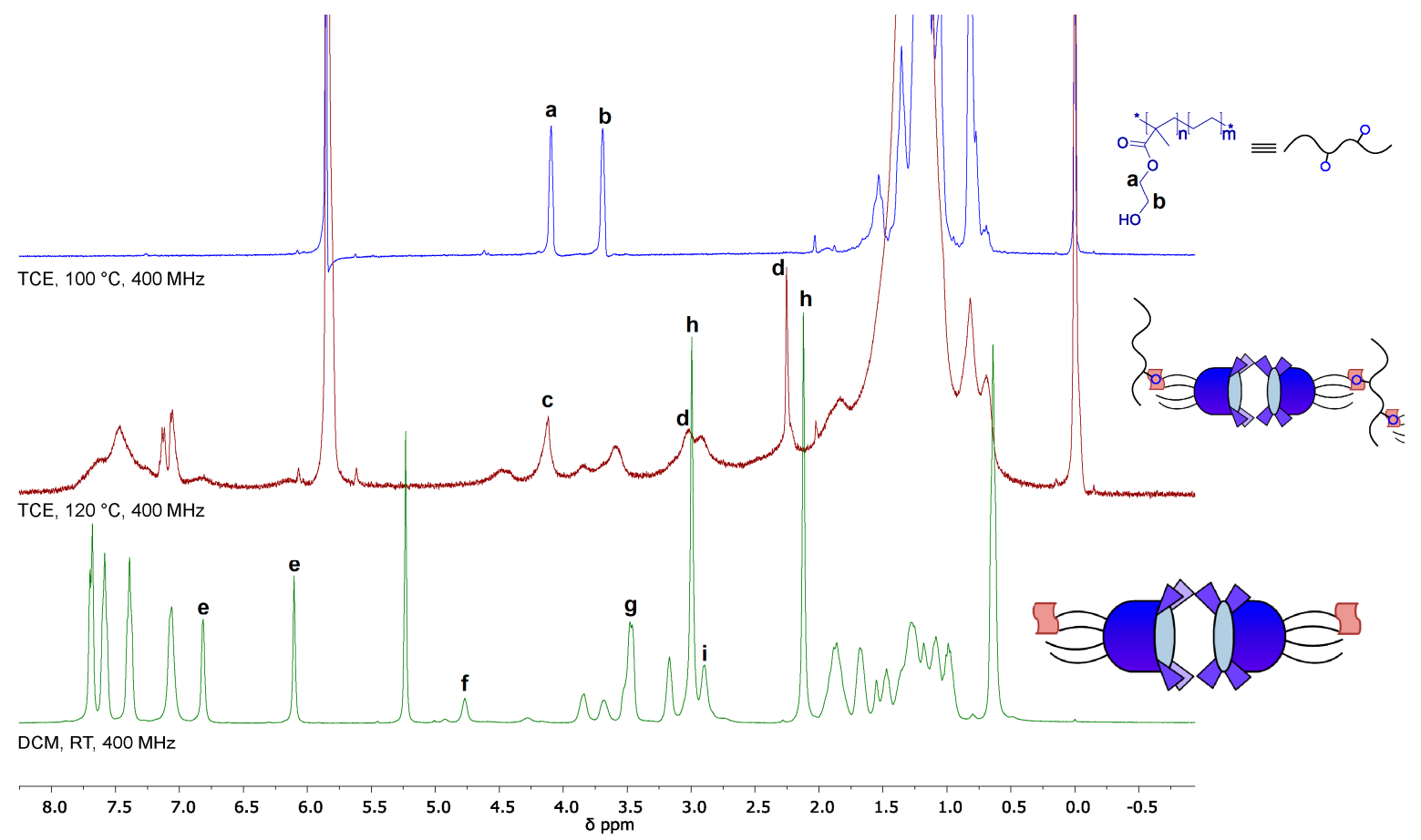

Figure 4. ${ }^{1} \mathrm{H}-\mathrm{NMR}$ spectra of pristine PE-HEMA (top spectrum, blue line), 4QxCav30.6 (middle spectrum, red line), and 4QxCavNCO (bottom spectrum, green line). Letters indexing in the middle spectrum: c PE-HEMA-C(O)OCH $\mathrm{CH}_{2} \mathrm{OC}(\mathrm{O}) \mathrm{NH}$, d ArCH . Letters indexing in the bottom spectrum: e $\mathrm{ArH}, \mathbf{f} \mathrm{OC}(\mathrm{O}) \mathrm{NH}, \mathbf{g ~ C H} \mathrm{NCO}_{2} \mathbf{h} \mathrm{ArCH}_{3}$, i OC(O)NHCH $\mathrm{NH}_{2}$. 
To test the processability, solution casting technique was employed. Firstly, the functionalized polymers were dissolved in tetrachloroethane (TCE) (Sigma Aldrich, St. Louis, MO, USA) at $100{ }^{\circ} \mathrm{C}$, then the obtained solutions were transferred into a polytetrafluoroethylene (PTFE) mold and the solvent was slowly evaporated at $120^{\circ} \mathrm{C}$. Thereby, thin transparent films with a thickness of around $100 \mu \mathrm{m}$ were obtained (Figure 5).

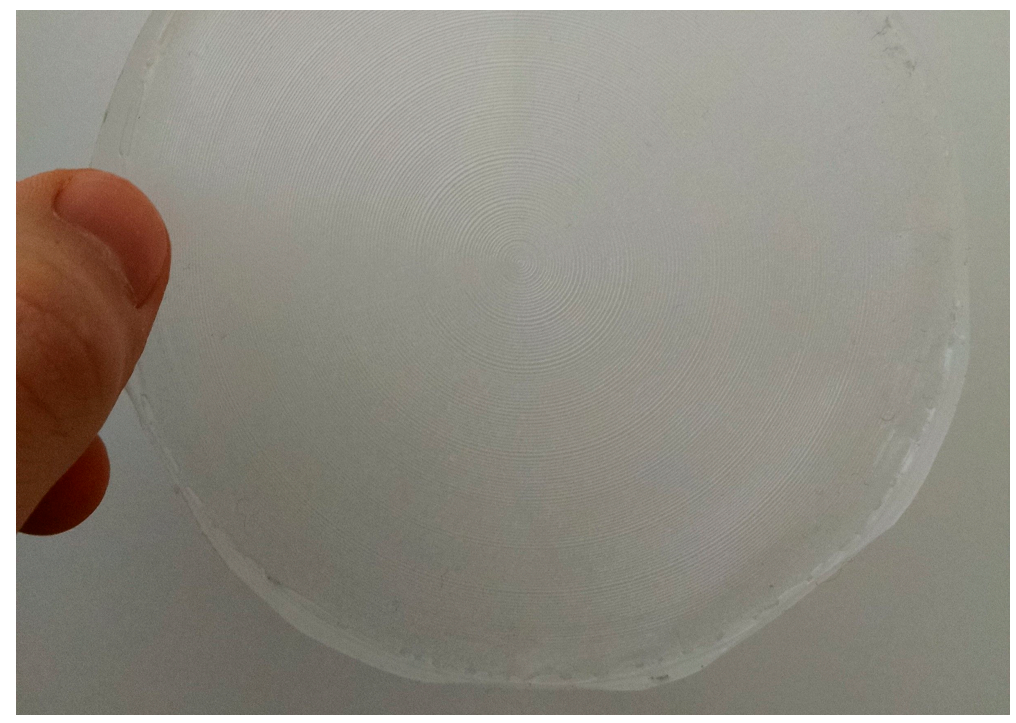

Figure 5. Thin transparent film of functionalized PE_HEMA obtained via solution casting.

The films were subsequently used to determine the oxygen barrier properties of pristine and velcrand functionalized films. The oxygen transmission rate for pristine and velcrand functionalized PE-HEMA as a function of velcrand content in $\mathrm{wt} \%$ is given in Figure $6 \mathrm{~A}$. Clearly, the introduction of the velcrand into the polymers leads to a significant increase in the oxygen transmission rate, therefore decreasing its barrier property towards oxygen. This is most likely caused by the decreased crystallinity of functionalized samples (see Table 1). Despite the small decrease in $X_{c}$ for materials with $1 \mathrm{wt} \%$ and $5 \mathrm{wt} \%$ of velcrand, a significant decrease in barrier property was observed. This can likely be explained by the increase in free volume caused by the bulky velcrand, which also adversely affects the oxygen barrier properties of polymers [23]. Sample 4QxCav1 presents an outlier with a far greater increased transmission than the sample with higher velcrand content, and additional defects in the sample are likely responsible.
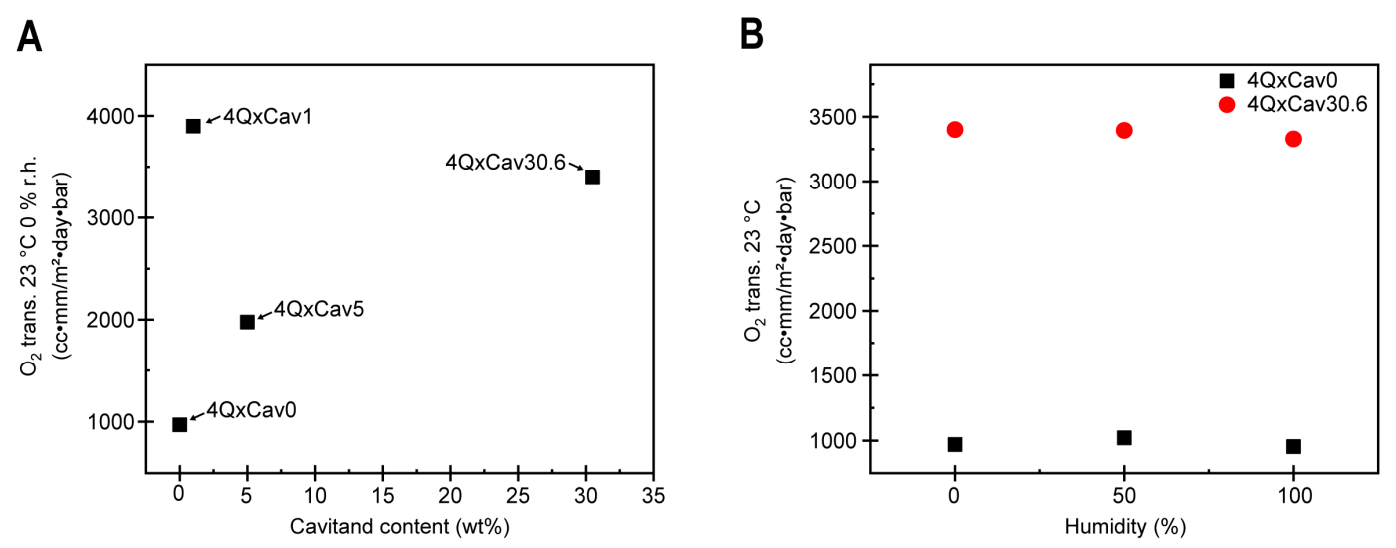

Figure 6. A: Oxygen transmission rates of pristine and velcrand functionalized PE-HEMA as a function of velcrand content in $\mathrm{wt} \%(0,1,5$, and $30.6 \mathrm{wt} \%)$. B: Influence of humidity on oxygen transmission of pristine and functional PE-HEMA. 
Additionally, the effect of humidity on oxygen transmission was investigated, measuring oxygen transmission at $0 \%, 50 \%$, and $100 \%$ relative humidity. The results of these measurements for pristine polymer (4Qx-Cav0) and 4QxCav30.6 are given in Figure 6B. No influence of humidity was apparent for either pristine or functionalized materials, showing the resilience of these materials towards water. This was unexpected in the case of PE-HEMA, as hydrogen bonds of HEMA should be disturbed by increased humidity. Most likely, the apolar nature of PE backbone chains shields the hydrogen bonds of HEMA from influences of increased humidity for this polymer with low HEMA content.

\section{Experimental}

Unless otherwise specified, chemicals and solvents were purchased from Sigma-Aldrich and used as received. $N, N$-Dimethylformamide (DMF) was dried over $4 \AA$ molecular sieves prior to use. Dichloromethane (DCM) was distilled and stored over $4 \AA$ molecular sieves. All other employed solvents were laboratory grade and were used as received. The PE-HEMA polymer used in this study was provided by SABIC $\left(\mathrm{M}_{\mathrm{n}}=16,200 \mathrm{~g} / \mathrm{mol}, \mathrm{M}_{\mathrm{w}}=63,000 \mathrm{~g} / \mathrm{mol}\right.$, Dispersity $=3.9$, and $0.91 \mathrm{~mol} \%$ of HEMA). The starting mono-hydroxyl methyl resorcinarene and the $4 \mathrm{QxCavOH}$ were prepared following published procedures $[19,27]$.

\subsection{Proton Nuclear Magnetic Resonance $\left({ }^{1} H-N M R\right)$}

${ }^{1} \mathrm{H}-\mathrm{NMR}$-spectra were recorded on a Bruker Avance $400(400 \mathrm{MHz})$ spectrometer (Bruker, Billerica, MA, USA) and a Bruker Avance 300 (300 MHz) at room temperature. Chemical shifts are reported in ppm. ${ }^{1} \mathrm{H}-\mathrm{NMR}$ chemical shifts are given in reference to the residual solvent peak at $7.26 \mathrm{ppm}$ in $\mathrm{CD}_{2} \mathrm{Cl}_{2}$ and at $2.50 \mathrm{ppm}$ in DMSO-d $\mathrm{d}_{6}$. High temperature nuclear magnetic resonance (HTNMR) spectra were recorded on a Bruker AVANCE III (400 MHz) (Bruker, Billerica, MA, USA) equipped with a cryogenically cooled probe head at $100{ }^{\circ} \mathrm{C}$ and $120^{\circ} \mathrm{C}$ in TCE- $\mathrm{d}_{2} \cdot{ }^{1} \mathrm{H}-\mathrm{NMR}$ chemical shifts are reported in ppm and given in reference to the residual solvent peak of TCE- $\mathrm{d}_{2}$ at $6.00 \mathrm{ppm}$.

\subsection{Fourier Transformed Infrared Spectroscopy (FTIR)}

FTIR-spectra were recorded on a Perkin Elmer Spectrum One equipped with a Golden Gate accessory (diamond ATR) (Perkin Elmer, Waltham, MA, USA).

\subsection{Differential Scanning Calorimetry (DSC)}

The DSC measurements were performed on a TA Instruments Q20 (TA Instrument, New Castle, DE, USA) equipped with a RCS 90 cooling system. About $3-5 \mathrm{mg}$ of polymeric sample was weighed inside an aluminum pan and subjected to DSC measurements under nitrogen atmosphere. Unless otherwise noted, polymers were screened twice from $-40{ }^{\circ} \mathrm{C}$ to $200{ }^{\circ} \mathrm{C}$ at a constant heating/cooling rate of $10 \mathrm{~K} \cdot \mathrm{min}^{-1}$. The $\mathrm{T}_{\mathrm{m}}$, and the melting enthalpy $\left(\mathrm{H}_{\mathrm{m}}\right)$ were determined from the second heating.

\subsection{Oxygen and Water Transmission}

Oxygen transmission rates were determined according to ISO 15,1052 at $23^{\circ} \mathrm{C}$, and at $0 \%$ r.h., $50 \%$ r.h., and at $100 \%$ r.h. The thickness of films, which was around $100 \mu \mathrm{m}$, was measured at varying locations and the average was used to report thickness corrected oxygen transmission rates.

\subsection{Synthesis of $4 Q x C a v N C O$}

The reaction was performed under dry condition. HDI $(0.5 \mathrm{~mL}, 3.11 \mathrm{mmol}, 8 \mathrm{eq})$ was inserted into a Shlenk flask and degassed. Subsequently, dichloromethane $(25 \mathrm{~mL})$ was added and the mixture cooled to $0{ }^{\circ} \mathrm{C}$. Then, $4 \mathrm{QxCavOH}(0.5 \mathrm{~g}, 0.41 \mathrm{mmol}, 1 \mathrm{eq})$, dissolved in DCM $(50 \mathrm{~mL})$, was added via syringe, followed by the addition of a drop of DBTDL as catalyst. The reaction was stirred overnight at room temperature. The solute was precipitated in cold $\left(0^{\circ} \mathrm{C}\right)$ diethylether, filtered, dried, redissolved in DCM and then precipitated into pentane. The obtained precipitate was filtered and dried, obtaining 
the desired product as a white powder $\left(0.39 \mathrm{~g}, 69 \%\right.$ yield). ${ }^{1} \mathrm{H}-\mathrm{NMR}\left(300 \mathrm{MHz}, \mathrm{CD}_{2} \mathrm{Cl}_{2}\right) \delta: 7.78-7.71$ $(\mathrm{m}, 4 \mathrm{H}), 7.70-7.63(\mathrm{~m}, 4 \mathrm{H}), 7.52-7.44(\mathrm{~m}, 4 \mathrm{H}), 7.15(\mathrm{~s}, 4 \mathrm{H}), 6.90(\mathrm{~s}, 2 \mathrm{H}), 6.19(\mathrm{~s}, 2 \mathrm{H}), 4.86(\mathrm{~s}, 1 \mathrm{H}), 4.1-3.74$ $(\mathrm{m}, 2 \mathrm{H}), 3.71-3.5(\mathrm{~m}, 4 \mathrm{H}), 3.25(\mathrm{~s}, 2 \mathrm{H}), 3.07(\mathrm{~s}, 6 \mathrm{H}), 3.02-2.84(\mathrm{~m}, 2 \mathrm{H}), 2.20(\mathrm{~s}, 6), 2.09-1.68(\mathrm{~m}, 8 \mathrm{H})$ 1.66-0.97 (m, 16H), $0.73(\mathrm{t}, \mathrm{J}=7.2 \mathrm{~Hz}, 9 \mathrm{H})$. MS (MALDI) m/z: $[\mathrm{M}+\mathrm{H}]^{+}$calcd for $\mathrm{C}_{84} \mathrm{H}_{77} \mathrm{~N}_{10} \mathrm{O}_{11}$, 1401.58; found, 1401.41 .

\subsection{Synthesis of Velcrand Functionalized Polyethylene}

Polymer functionalization with velcrand was carried out according to the following general procedure, exemplified for 4QxCav30.6: The reaction was performed under dry conditions.

PE-HEMA (0.5 g) with $0.91 \%$ of HEMA groups, was dissolved in toluene $(50 \mathrm{~mL})$ at $80{ }^{\circ} \mathrm{C}$. Then, the $4 \mathrm{QxCavNCO}(0.28 \mathrm{~g}, 1 \mathrm{eq}$ with respect to $\mathrm{OH}$ groups) was added as a solid. After dissolution of the velcrand, two drops of DBTDL were added to function as a catalyst. The mixture was stirred at $80{ }^{\circ} \mathrm{C}$ for $4 \mathrm{~h}$. The reaction was quenched in acetone, resulting in precipitation of a white powder. Filtration and drying of the precipitate gave the product as a white powder.

\section{Conclusions}

A self-dimerizing velcrand in kite conformation functionalized at the lower rim with an isocyanate group was synthesized. This velcrand, namely 4QxCavNCO, was grafted onto PE-HEMA, a polymer with free hydroxyl groups, via urethane bond formation. The successful synthesis of these functionalized polyolefins was confirmed via FTIR and ${ }^{1} \mathrm{H}-\mathrm{NMR}$ spectroscopy. Transparent films of functional polymers were obtained by solution casting and slow evaporation of the solvent. Thereby obtained films were tested for their oxygen transmission, which was found to sequentially increase with increasing velcrand concentration. This lackluster performance can be a result of the severely reduced degree of crystallinity $\left(X_{\mathrm{C}}\right)$ and increased free volume due to the introduction of the bulky velcrand, suggesting that the expected increased interfacial cohesion between chains in the amorphous phase, which is associated with increased barrier properties, did not occur.

Most significantly, 4QxCavNCO velcrand provides a tool to introduce reversible supramolecular cross-linking into polymers [19].

Author Contributions: Conceptualization, R.P. and E.D.; methodology, J.T.; validation, R.P., J.V. and E.D.; formal analysis, J.T.; investigation, J.T.; resources, E.D., R.P, and M.S.; data curation, M.S. and J.V.; writing-original draft preparation, J.T.; writing - review and editing, R.P., J.V and E.D.; project administration, R.P.; funding acquisition, M.S. and E.D.

Funding: This work is supported by the SUPRAmolecular polyolefins as oxygen BARRIER materials (SUPRABARRIER) Marie Skłodowska Curie project, which is funded through the European Union Eighth Framework Program (H2020-MSCA-ITN-2014) under the Grant Agreement No. 642929.

Acknowledgments: The Centro Interfacoltà di Misure "G. Casnati" of the University of Parma is kindly acknowledged for the use of NMR and MALDI-MS facilities. We thank Peter Neuteboom for providing the PE-HEMA polymers used in this study.

Conflicts of Interest: The authors declare no conflict of interest. The funders had no role in the design of the study; in the collection, analyses, or interpretation of data; in the writing of the manuscript, or in the decision to publish the results.

\section{References}

1. Pinalli, R.; Pedrini, A.; Dalcanale, E. Cavitands. In Comprehensive Supramolecular Chemistry II; Atwood, J.L., Ed.; Elsevier: Amsterdam, The Netherlands, 2017; pp. 87-115.

2. Hooley, R.J.; Rebek, J. Chemistry and catalysis in functional cavitands. Chem. Biol. 2009, 16, $255-264$. [CrossRef] [PubMed]

3. Natarajan, N.; Brenner, E.; Sémeril, D.; Matt, D.; Harrowfield, J. The use of resorcinarene cavitands in metal-based catalysis. Eur. J. Org. Chem. 2017, 2017, 6100-6113. [CrossRef]

4. Mirabaud, A.; Mulatier, J.-C.; Martinez, A.; Dutasta, J.-P.; Dufaud, V. Merging host-guest chemistry and organocatalysis for the chemical valorization of $\mathrm{CO}_{2}$. Catal. Today 2017, 281, 387-391. [CrossRef] 
5. Vidal, D.; Costas, M.; Lledó, A. A deep cavitand receptor functionalized with Fe(II) and Mn(II) aminopyridine complexes for bioinspired oxidation catalysis. ACS Catal. 2018, 8, 3667-3672. [CrossRef]

6. Pinalli, R.; Dalcanale, E.; Ugozzoli, F.; Massera, C. Resorcinarene-based cavitands as building blocks for crystal engineering. CrystEngComm 2016, 18, 5788-5802. [CrossRef]

7. Pochorovski, I.; Diederich, F. Development of redox-switchable resorcin[4]arene cavitands. Acc. Chem. Res. 2014, 47, 2096-2105. [CrossRef] [PubMed]

8. Pinalli, R.; Brancatelli, G.; Pedrini, A.; Menozzi, D.; Hernández, D.; Ballester, P.; Geremia, S.; Dalcanale, E. The origin of selectivity in the complexation of $\mathrm{N}$-methyl amino acids by tetraphosphonate cavitands. J. Am. Chem. Soc. 2016, 138, 8569-8580. [CrossRef] [PubMed]

9. Brancatelli, G.; Dalcanale, E.; Pinalli, R.; Geremia, S. Probing the Structural Determinants of Amino Acid Recognition: X-Ray Studies of Crystalline Ditopic Host-Guest Complexes of the Positively Charged Amino Acids, Arg, Lys, and His with a Cavitand Molecule. Molecules 2018, 23, 3368. [CrossRef] [PubMed]

10. Ghang, Y.-J.; Perez, L.; Morgan, M.A.; Si, F.; Hamdy, O.M.; Beecher, C.N.; Larive, C.K.; Julian, R.R.; Zhong, W.; Cheng, Q.; et al. Anionic deep cavitands enable the adhesion of unmodified proteins at a membrane bilayer. Soft Matter 2014, 10, 9651-9656. [CrossRef] [PubMed]

11. Bontempi, N.; Biavardi, E.; Bordiga, D.; Candiani, G.; Alessandri, I.; Bergese, P.; Dalcanale, E. Probing lysine mono-methylation in histone $\mathrm{H} 3$ tail peptides with an abiotic receptor coupled to a non-plasmonic resonator. Nanoscale 2017, 9, 8639-8646. [CrossRef] [PubMed]

12. Clément, P.; Korom, S.; Struzzi, C.; Parra, E.J.; Bittencourt, C.; Ballester, P.; Llobet, E. Deep cavitand self-assembled on Au NPs-MWCNT as highly sensitive benzene sensing interface. Adv. Funct. Mater. 2015, 25, 4011-4020. [CrossRef]

13. Tudisco, C.; Fragalà, M.E.; Giuffrida, A.E.; Bertani, F.; Pinalli, R.; Dalcanale, E.; Compagnini, G.; Condorelli, G.G. Hierarchical route for the fabrication of cavitand-modified nanostructured $\mathrm{ZnO}$ fibers for volatile organic compound detection. J. Phys. Chem. C 2016, 120, 12611-12617. [CrossRef]

14. Pinalli, R.; Dalcanale, E. Supramolecular sensing with phosphonate cavitands. Acc. Chem. Res. 2013, 46, 399-411. [CrossRef] [PubMed]

15. Pinalli, R.; Pedrini, A.; Dalcanale, E. Environmental gas sensing with cavitands. Chem Eur. J. 2018, 24, 1010-1019. [CrossRef] [PubMed]

16. Azov, V.A.; Beeby, A.; Cacciarini, M.; Cheetham, A.G.; Diederich, F.; Frei, M.; Gimzewski, J.K.; Gramlich, V.; Hecht, B.; Jaun, B.; et al. Resorcin[4]arene Cavitand-Based Molecular Switches. Adv. Funct. Mater. 2006, 16, 147-156. [CrossRef]

17. Moran, J.R.; Karbach, S.; Cram, D.J. Cavitands: Synthetic Molecular Vessels. J. Am. Chem. Soc. 1982, 104, 5826-5828. [CrossRef]

18. Cram, D.J.; Choi, H.-J.; Bryant, J.A.; Knobler, C.B. Solvophobic and Entropic Driving Forces for Forming Velcaplexes, Which are Four-Fold, Lock-Key Dimers in Organic Media. J. Am. Chem. Soc. 1992, 114, 7748-7765. [CrossRef]

19. Pirondini, L.; Stendardo, A.G.; Geremia, S.; Campagnolo, M.; Samorì, P.; Rabe, J.P.; Fokkens, R.; Dalcanale, E. Dynamic Materials via Metal-Directed and Solvent-Driven Self-Assembly of Cavitands. Angew. Chem. Int. Ed. 2003, 42, 1384-1387. [CrossRef] [PubMed]

20. Kwak, M.-J.; Paek, K. Molecular Engineering. Part 14. Self-Assembled Oligovelcraplexes by $\pi-\pi$ Stacking Interaction and Metal Coordination. Bull. Korean Chem. Soc. 2007, 28, 1440-1442. [CrossRef]

21. Tancini, F.; Rampazzo, E.; Dalcanale, E. Interplay Between Cyclization and Polymerization in Ditopic Cavitand Monomers. Aust. J. Chem. 2010, 63, 646-652. [CrossRef]

22. Ihm, H.; Ahn, J.-S.; Lah, M.S.; Ko, Y.H.; Paek, K. Oligobisvelcraplex: Self-Assembled Linear Oligomer by Solvophobic $\pi-\pi$ Stacking Interaction of Bisvelcrands Based on Resorcin[4]arene. Org. Lett. 2004, 6, 3893-3896. [CrossRef] [PubMed]

23. Lagaron, J.M.; Catalá, R.; Gavara, R. Structural characteristics defining high barrier properties in polymeric materials. Mater. Sci. Technol. 2004, 20,1-7. [CrossRef]

24. Moran, J.R.; Ericson, J.L.; Dalcanale, E.; Bryant, J.A.; Knobler, C.B.; Cram, D.J. Vases and kites as cavitands. J. Am. Chem. Soc. 1991, 113, 5707-5714. [CrossRef] 
25. Cormier, C.M.; Wunderlich, B. Heat of fusion of polyethylene. J. Polym. Sci. 1967, 5, 987-988. [CrossRef]

26. Hirschmann, R.P.; Kniseley, R.N.; Fassel, V.A. The infrared spectra of alkyl isocyanates. Spectrochim. Acta 1965, 21, 2125-2133. [CrossRef]

27. Hauke, F.; Myles, A.J.; Rebek, J. Lower rim mono-functionalization of resorcinarenes. Chem. Commun. 2005, 4164-4166. [CrossRef] [PubMed]

Sample Availability: Samples of isocyanate functionalized velcrand and functionalized polymers are available from the authors.

(c) 2019 by the authors. Licensee MDPI, Basel, Switzerland. This article is an open access article distributed under the terms and conditions of the Creative Commons Attribution (CC BY) license (http:/ / creativecommons.org/licenses/by/4.0/). 